\title{
Perimenstrüel Distresin Hafifletilmesinde Refleksolojinin Etkinliğinin İncelenmesi
}

\author{
Examination of Effects of Reflexology on Relieving Perimenstural Distress
}

\author{
Nursen BOLSOY ${ }^{1}$, Ahsen ȘíRíN 20 \\ ${ }^{1}$ Manisa Celal Bayar Üniversitesi, Sağlık Bilimleri Fakültesi, Ebelik Bölümü, Manisa, Türkiye \\ 2 İstanbul Arel Üniversitesi, Sağlık Bilimleri Yüksekokulu, Hemşirelik Bölümü, İstanbul, Türkiye
}

ÖZ

\begin{abstract}
Amaç: Araştırmada perimenstrüel distresi hafifletmede refleksolojinin etkisininin incelenmesi amaçlanmıştır.
Yöntem: Randomize kontrollü deneysel bir araştırmadır. Araştırma evrenini, 585 genç kadın oluşturmuştur. Perimenstrüel distres puanı yüksek olan 94 katılımcıdan tesadüfi örnekleme yöntemi ile 47 kişilik iki grup oluşturulmuştur. Değişik nedenlerden dolayı çalışma dışı kalanlar olmuştur. Araştırmanın refleksoloji grubu 31 kişi, rutin tedavi grubu (NSAID Tedavisi) 33 kişi ile tamamlanmıştır. Her iki gruba da araştırmacı tarafından perimenstrüel distresi hafifletmeye yönelik hemşirelik eğitimi verilmiştir. Katılımcılar, iki siklus refleksoloji öncesi, iki siklus refleksoloji süresince ve iki siklus refleksoloji sonrasında olmak üzere altı siklus izlenmiştir. Araştırmacı tarafından iki siklus süresince (sekiz seans), haftada bir defa, yarım saat süre ile kulaklara, ellere ve ayaklara refleksoloji uygulanmıştır. Veri toplama aracı olarak; Birey Tanıtım Formu, Birey İzlem Formu" ve "Menstrüel Distres Şikâyet Listesi (MDQ)" kullanılmıştır.

Bulgular: Uygulanan refleksoloji sonucu, menstrüel dönem semptomlarında \%46.54, premenstrüel dönem semptomlarında \%44.99 azalma olmuştur. Refleksoloji uygulanan birinci siklusta; menstrüel ve premenstrüel dönemlerde refleksoloji grubu ile rutin tedavi grubunun puan ortalamaları açısından istatistiksel olarak anlamlı bir fark bulunmazken ( $\mathrm{p}=0.33,0.35)$, ikinci siklusta menstrüel ve premenstrüel dönemlerde refleksoloji grubunun puanlarının rutin tedavi grubundan daha düşük olduğu ve bunun istatistiksel olarak anlamlı olduğu bulunmuştur $(\mathrm{p}=0.02,0.01)$. Refleksoloji bırakıldıktan sonra da anlamlı fark devam etmiştir.
\end{abstract}

Sonuç: Perimenstrüel yakınmaları olan genç kadınlar için refleksoloji uygulaması semptomların şiddetini azaltıcı tamamlayıcı bir tedavi olarak önerilebilir.

Anahtar Kelimeler: Premenstrual sendrom, Dismenore, Refleksoloji, Tamamlayıc tedavi.

\section{ABSTRACT}

Objective: The aim of this study was to investigate the effect of reflexology on alleviating perimenstrual distress.

Methods: This is a randomized controlled experimental study. The research population was 585 young women. Two groups of 47 were randomly selected from 94 participants with high perimenstrual distress scores. There were those who left the study for different reasons. The reflexology group of the study was completed with 31 people and the routine treatment group (NSAID Treatment) was completed with 33 people. Both groups were given nursing training to alleviate perimenstrual distress by the researcher. Participants were followed by six cycles, two cycles before reflexology, two cycles during reflexology and two cycles after reflexology. During the two cycles (eight sessions), reflexology was applied to the ears, hands and feet once a week for half an hour. As data collection tool; "The Personal Introduction Form", "The Personal Pursuit Form" and "The Menstrual Distress Questionaire (MDQ)" were used.

Results: Reflexology decreased $46.54 \%$ of menstrual period symptoms and $44.99 \%$ of premenstrual symptoms. In the first cycle applied reflexology; There was no statistically significant difference between the mean scores of reflexology group and routine treatment group in menstrual and premenstrual periods $(\mathrm{p}=0.33,0.35)$. In the second cycle, the reflexology group scores were lower in menstrual and premenstrual periods than in the routine treatment group, which was statistically significant $(p=0.02,0.01)$. Significant difference persisted after reflexology was discontinued.

Sorumlu Yazar: Nursen BOLSOY

Manisa Celal Bayar Üniversitesi, Sağlık Bilimleri Fakültesi, Ebelik Bölümü, Manisa, Türkiye nursenbolsoy@gmail.com

*Bu makale 2008, Ege Üniversitesi Sağlık Bilimleri Enstitüsü Doktora tezidir.

Geliş Tarihi: 18.09.2019 - Kabul Tarihi 08.12.2019 
Conclusion: For young women with perimenstrual complaints, reflexology may be recommended as a complementary treatment to reduce the severity of symptoms.

Key words: Premenstrual syndrome, Dysmenorrhea, Reflexology, Complementary therapies.

\section{GíRiș}

Menstrüel siklusun hem premestrüel, hem de menstrüel döneminde ortaya çıkan yakınmalara perimenstrüel distres denilmektedir (1-3). Menstrüasyon başlangıcından 7-10 gün öncesinde ortaya çıkabilen, menstrüasyonun başlamasından itibaren birkaç günde ortadan kaybolan, çoğu siklusta tekrarlayan, fiziksel, psikolojik, davranışsal semptomlara premenstrüel sendrom (PMS), menstrüasyon süresince tanımlanan ağrıya ise dismenore denilmektedir (4-7).

Dismenore kadınlarda en çok görülen jinekolojik yakınmadır (8-11) Primer dismenore pelvik bir patoloji ile ilişkili değildir. Genellikle ovulasyonlu sikluslardan sonra görülür. Menarştan sonra 1-2 yılda ovulasyonun yerleşmesi ile ortaya çıkar, 23-27 yaşlar arasında şiddetinde artış vardır ve daha sonra giderek azalır $(7,8)$.

Literatürde dismenorenin üreme çağındaki kadınların \%20-90'nını çeşitli derecelerde etkilediği, bunların \%7-15'inin çok şiddetli ağrı yaşadıkları ve her yıl pek çok işgücü (çalışma ve okul) kaybına neden olduğu belirtilmektedir (9-11). Bir başka deyişle, tüm kadınların \%25'inin, adölesanların \%90'nının dismenore yaşadıkları tahmin edilmektedir. Durain (2004), adölesanlarda okul devamsızlığının birinci sebebinin dismenore olduğunu belirtmektedir (10).

Yapılan bir çalışmada dismenoreli öğrencilerin sadece \%14'ünün bir doktora başvurduğu, \%49'unun ise semptomları için okul hemşiresinden yardım istediği saptanmıştır (9). Bu bulgu, hemşirelerin danışmanlık ve rehberlik fonksiyonlarının, hemşirelik işlevi olarak uygulayabileceği ve öğretebileceği nonfarmakolojik girişimlerin önemini ortaya koymaktadır.

Premenstrüel sendrom ise; fertil çağ boyunca kadınların yaklaşık olarak \%90'nını etkileyen yaygın bir bozukluktur (12). Kadınlarda günlük aktiviteleri ve yaşam kalitesini etkileyecek çeşitli derecede semptomlara neden olmaktadır. En sık rastlanan semptomlar: çabuk sinirlenme, karında gerginlik ve şişlik, göğüslerde ağrı ve şişlik, yorgunluk ve halsizlik, iç sıkıntısı, sosyal faaliyetlere karşı isteksizlik, ağlama isteği, baş ağrısı, dikkatini toplayamama, mide bulantısı, ishal, bel ağrısı, karında ağrı ve kramplardır $(7,11,13)$. Etyolojisi ve patogenezi henüz tam olarak bilinmeyen PMS'nin spesifik bir tedavisi yoktur. Bu nedenle farklı tedavi seçeneklerinin entegre edildiği bütünsel bir yaklaşım önerilmektedir (14) Tedavi genellikle, farmakolojik olmayan stratejilerden, analjezik, antidepresan ilaçlardan ve hormonal stratejilerden oluşur. Cerrahi seçenekler ise son çare olduğu durumlarda önerilir (15). Literatürde, PMS ile baş etmede bazı yaşam tarzı değişikliklerinin, tamamlayıcı ve integratif tedavilerin (masaj, egzersiz, diyet değişiklikleri, relaksasyon teknikleri, akupunktur, refleksoloji vb.) başarılı olduğu konusunda yayınlar vardır (16-25) Fakat tedaviler araştırma sayılarının azlığından, bazılarında da araştırma yöntemleri veya örneklem sayılarının uygun bulunmamasından dolayı birçok sağlık profesyoneli tarafından şüpheyle karşılanmaktadır (24, 26, 27). Buna karşın perimenstrüel distres yaşayan kadınlar arasında kullanımları oldukça sıktır ve kullanan kadınların sayısı da her geçen gün artış göstermektedir. Bunun nedeni, genel sağlık için tavsiye edilebilir yöntemler olmaları ve sağlık riski içermemeleridir (16,24,28,29). Tamamlayıcı ve integratif tedavi yöntemlerinden birisi olan refleksoloji (29-31), vücudun spesifik organ ve bölgelerinin küçük bir aynası kabul edilen kulaklar, eller ve ayaklardaki refleks noktalarının masajla uyarılması anlamına gelir $(23,32,33)$. Antik çağlardan beri 
kullanılmakta olan refleksoloji, günümüzde ABD başta olmak üzere İngiltere, Belçika ve Fransa gibi Avrupa ülkelerinde çok yaygın olarak kullanılmaktadır (28,32,34-36) Refleksolojiyle ilgili anekdotal kanıtların çok fazla olmasına karşın bilimsel kanıt sayısı azdır. Fakat son yıllarda bilimsel çalışmalarda ciddi bir artış söz konusudur. Randomize kontrollü çalışmalar ile refleksolojinin PMS ve dismenorenin hem fiziksel hem de psikolojik semptomlarını azalttığı belirlenmiştir $(23,37)$. Ülkemizde perimentrüel distresi hafifletmek için refleksolojiyle yapılan bir çalışmaya rastlanamamıştır. Bu araştırma, perimenstrüel distresi hafifletmede refleksolojinin etkisini incelenmek amacı ile yapılmıştır.

\section{GEREÇ VE YÖNTEMLER}

\section{Araştırmanın Tipi}

Randomize kontrollü deneysel bir araştırma olarak yapılmıştır.

\section{Araştırmanın Evren ve Örneklemi}

Evreni bir üniversitenin hemşirelik bölümünde 2006-2007 öğretim y1lında 1., 2. ve 3. sınıflarda lisans öğrenimi gören 585 kız öğrenci oluşturmuştur. Araştırma tamamlanmadan mezun olacakları ve araştırma için gerekli olan iletişim kopacağı düşüncesiyle 4. sınıf öğrenciler araştırma dışı bırakılmıştır.

Araştırmanın yapıldığı tarihte okulda bulunan ve araştırmaya katılmayı kabul eden 400 katılımcıya Birey Tanıtım Formu (BTF) ve Menstrüel Distres Şikâyet Listesi (Menstruel Distress Questionnaire -MDQ) doldurtulmuştur. Araştırmaya dahil edilme kriterlerine uyan 237 katılımcıdan MDQ puanları premenstrüel ve menstrüel dönemlerde ortanca puanın üzerinde puan alan 94 katılımcı örneklemi oluşturmuşstur. Prementrüel dönem ortanca puanı; 37.0, mensrüel dönem ortanca puanı; 51.0, menstrüasyon sonrası dönem ortanca puanı; 12.0 olarak belirlenmiştir

\section{Araştırmaya Dahil Edilme Kriterleri}

1.Araştırmaya katılmaya gönüllü olan

2.Son altı aydır düzenli menstrüasyon gören,

3.Menstrüel siklusu 22-35 gün arasinda olan,

4.Menstrüasyon süresi yedi günden uzun olmayan,

5.Oral kontraseptif ya da RİA kullanmayan,

6.Jinekolojik sorunu olmayan,

7.Psikiyatrik sorunu olmayan,

8.Daha önce perimenstrüel distres tedavisi almamış olan,

9.Son üç aydır kronik bir rahatsızlığı olmayan ve büyük bir operasyon geçirmeyen.

10.Refleksoloji uygulanmasına engeli bulunmayan.

\section{Araștırmadan Dıșlanma Kriterleri}

1.Araştırma yapıldığı tarihte okulda bulunmayan

2.Dahil Edilme Kriterlerini sağlamayan, 
3.Premenstrüel, menstrüel ve menstrüasyon sonrası dönemin puanları eşit olan ve menstrüasyon sonrası dönemin puanları yüksek olan olgular ölçeği doğru doldurmadıkları veya başka bir rahatsızlıktan etkilenmiş olacağı düşüncesiyle örnekleme dahil edilmemiştir.

Örneklem grubuna giren katılımcılar listelenerek tesadüfi sayılar tablosuna göre 47 kişilik iki gruba ayrılmıştır. Gruplar; deney (refleksoloji) grubu ve kontrol (rutin tedavi) grubu şeklinde oluşturulmuştur. CONSORT akış planı şekil 1'de verilmiştir.

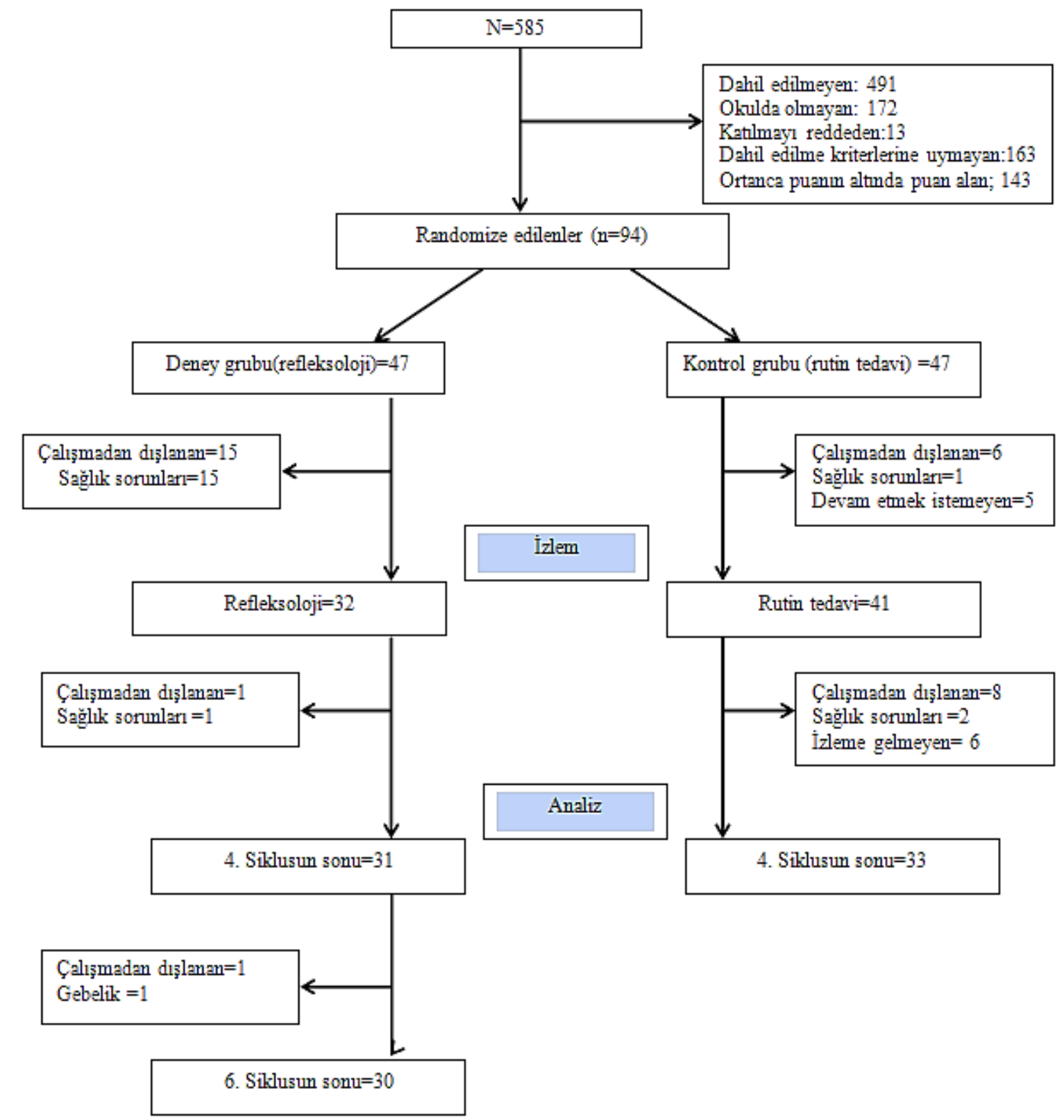

Şekil 1. CONSORT Akış Planı

\section{Veri toplama Yöntemi}

Her iki gruptaki katılımcılar davet edilerek araştırma hakkında bilgi verilmiş ve yazılı onamları alınmıştır. Daha sonra menstrüel siklusları hesaplanarak menstrüasyonun bitimine (siklusun 5-7.günlerinde) gelecek şekilde görüşmek üzere randevu verilmiştir. İlk görüşmede Birey İzlem Formu (BiF) ve MDQ doldurtulmuştur. Ikinci görüşmede tekrar BiF ve MDQ doldurtulmuş ve sonrasında PMS ve dismenoreyi hafifletmeye yönelik hemşirelik eğitimi 
yapılmıştır. Eğitim sonunda tekrar bakabilmeleri ve hatırlatıcı olması için araştırmacı tarafından hazırlanan eğitim kitapçı̆̆ı verilmiştir.

Rutin tedavi grubu iki siklusun sonunda; üniversitenin Sağlık Spor Daire Başkanlığı Üreme Sağlığı Bölümü'ne yönlendirilmiştir. Orada çalışmadan haberdar olan ve hizmeti yürüten hekim tarafından sağlık kontrolleri yapılarak rutin tedavileri (NSAID tedavi) planlanmıştır ve iki siklus daha görüşülmüş, BiF ve MDQ doldurtulmuştur. Grup iki siklus tedavi öncesi, iki siklus tedavi süresince olmak üzere dört siklus izlenmiştir.

Refleksoloji grubundaki katılımcılara iki siklusun sonunda; refleksoloji uygulama eğitimi almış aynı araştırmacı tarafından refleksoloji masajına başlanmıştır. Refleksoloji araştırmacının çalıştığı kurumda, rahat koltukların bulunduğu, sakin, araştırmacı ve katılımcı dışında kimsenin bulunmadığı bir odada yapılmıştır. Ayakların refleksoloji öncesi temizliği için hazır paketlerde satılan ıslak havlular kullanılmıştır. Refleksoloji masajı esnasında eller ve ayaklarda kayganlığı sağlamak için bitkisel yağ içeren bebek yağı kullanılmıştır. Hassas ya da acıyan alanlar hem refleksoloji masajı uygulanan kişilerin beden ifadelerinden hem de kişiye sorularak belirlenmiş ve daha sonra kaydedilmiştir. İletişim esnasında ve gözlemle elde edilen bilgiler bir defter tutularak kaydedilmiştir. Bir sonraki seansta daha önce kaydedilmiş olan hassas ya da acıyan alanlar kontrol edilmiştir. Araştırmacı tarafından iki siklus süresince (sekiz seans), haftada bir defa, yarım saat süre ile kulaklar, eller ve ayaklardaki refleks noktalarına refleksoloji masajı uygulanmıştır. Refleks noktası olarak Oleson ve Flocco (1993) tarafından kullanılan noktaların aynı olması tercih edilmiştir. Over, uterus, hipofiz ve endokrin sistem, solar pleksus, adrenal bez, böbrekler, sempatik sinir sistemi, Çinlilerin kulaktaki Shen men ve hoku (kalın bağırsak) noktaları kullanılmıştır (Şekil 2). Refleksoloji grubundaki katılımcılar, iki siklus refleksoloji öncesi, iki siklus refleksoloji süresince ve iki siklus da refleksoloji bırakıldıktan sonra olmak üzere altı siklus izlenmiştir. Her izlemde BiF ve MDQ doldurtulmuştur.

\section{Veri Toplamada Kullanılan Araçlar}

Araştırmada veri toplama aracı olarak "Birey Tanıtım Formu (BTF)", "Birey İzlem Formu (BIFF)" ve "Menstrüel Distres Şikâyet Listesi (Menstruel Distress Questionnaire MDQ)" kullanılmıştır. Katılımcıların, sosyo-demografik, sağlık, obstetrik, menstrüel özelliklerini ve alışkanlıklarını sorgulayan "BTF" ve "BİF" konuya ilişkin literatür ışığında araştırmacı tarafından hazırlanmıştır. Kadınların menstrüel yakınmalarının saptanması amacıyla kullanılan MDQ, 1968'de Moss'un geliştirdiği bir ölçektir. Türkçe geçerlilik ve güvenirliliği Kızılkaya ve Tuncel tarafından (1994) yapılarak Türkiye'de kullanıma kazandırılmıştır (38). Kızılkaya ve Tuncel'in çalışmasındaki cronbach alfa değerleri 0.71 ile 0,97 arasında değişmektedir. Bu çalışmada cronbach alfa değeri 0.94, premenstrüel dönem 0.91 , menstrüel dönem 0.89 ve menstrüasyon sonrası dönem 0.92 olarak belirlenmiştir.

Ölçek 47 semptomdan ve sekiz alt semptom grubundan oluşmaktadır. Bunlar; ağrı, su retansiyonu, otonomik reaksiyon, negatif duygulanım, konsantrasyon bozukluğu, davranış değişikliği, canlanma ve kontrol'dür. Şikayetler, premenstrüel, menstrüel ve menstrüasyon sonrası dönem için ayrı ayrı olarak 5 basamaklı ölçek ile 0'dan 4'e kadar puanlanmaktadır.

0-belirti yok

$1-\mathrm{az}$ 


\section{2-orta şiddette}

\section{3 -şiddetli}

4-çok şiddetli olarak ifade edilmektedir.
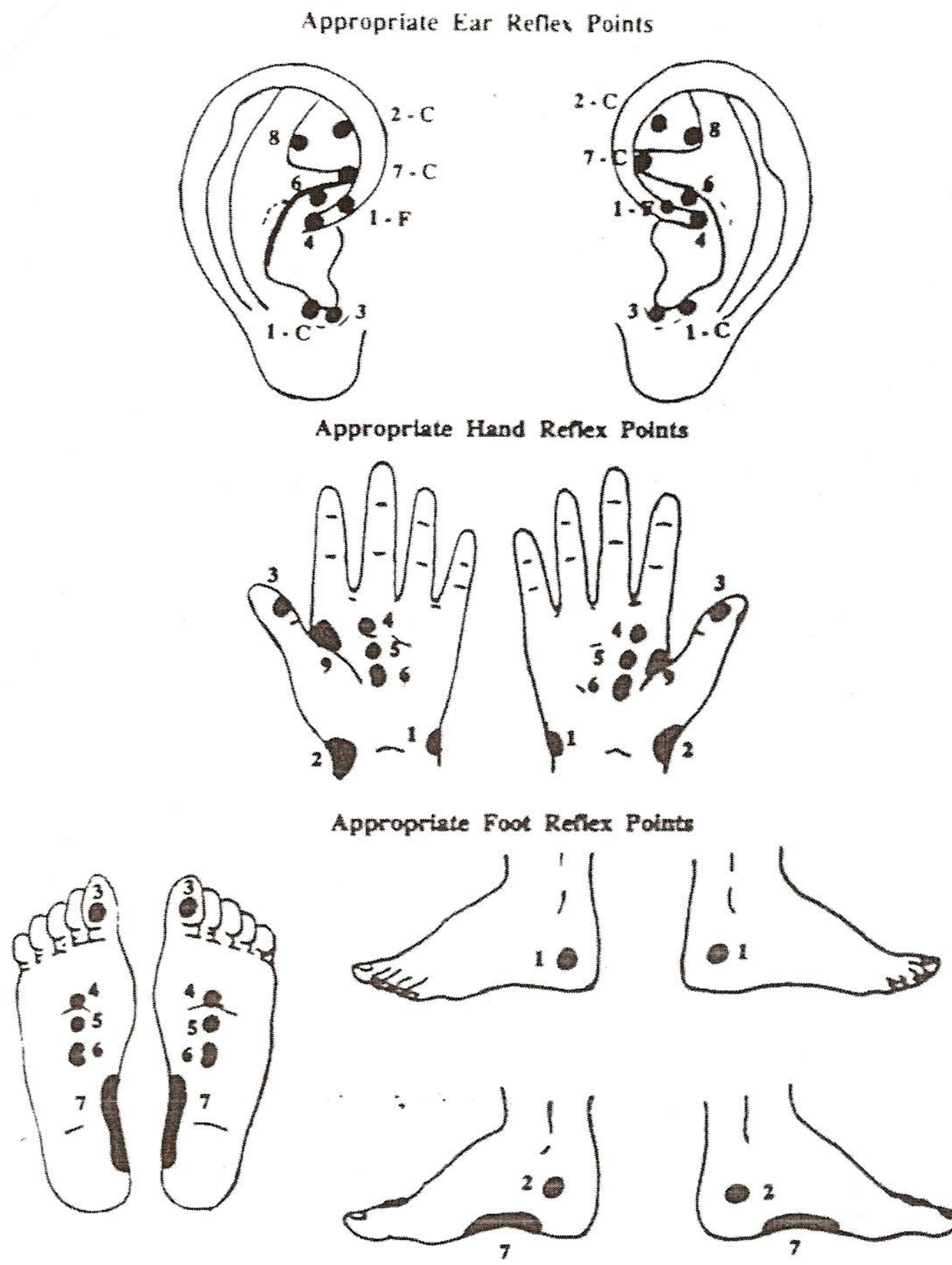

Şekil 2. Perimentrüel Distreste Manuel Bası İçin; Kulak, El ve Ayaktaki Refleks Noktaları

$1=$ over, $2=$ uterus, $3=$ hipofiz ve endokrin sistem, $4=$ solar pleksus, $5=$ adrenal bez, $6=$ böbrekler, $7=$ sempatik sinir sistemi, 8= Çinlilerin kulaktaki Shen men noktası, 9= Çin meridyen noktası hoku veya kalın bağırsak. Çinlilerin ve Fransızların kulak noktaları şemalarında farklılıklar vardır. Kulak resmi üzerindeki “C”; Çinlilerin sunumundan, "F”; Fransızların sunumundan alınmıştır. 


\section{Verilerin Analizi}

Verilerin değerlendirilmesi için sayı, yüzde dağılımı, ki-kare testi, Fisher's ki-kare önemlilik testi, sayısal öçümler için Paired Sample T Test, Independent Sample T Test ve Menstrüel Distres Şikayet Listesinin güvenirlilik analizi (cronbach alfa) kullanılmıştır. İstatistiksel analizler sonucunda $p$ değeri 0.05 'in altında ise anlamlı olarak kabul edilmiştir

\section{Araştırmanın Etik Yönü}

Çalışmaya başlamadan önce Etik Kurul Onayı (08/12/2006 tarihli 2006-109 sayıl1) ve kurum izni (21/12/2006 tarihli B.30.2.EGE. 0.82.00.00-2331 sayılı) alınmıştır. Örneklem seçim aşamasında tüm katılımcılara araştırmanın amacı açıklanmış bilgilendirilmiş sözlü onamları ve uygulama aşamasında bilgilendirilmiş yazılı onamları alınmıştır.

\section{BULGULAR}

Örneklemi oluşturan 64 katılımcının demografik özellikleri Tablo 1'de sunulmuştur. Gruplar arasında demografik özellikler ve alışkanlıklar açısından fark olmamasına özen gösterilmiştir. Katılımcıların sınıflarına, yaş gruplarına, ikamet yerlerine, medeni durumlarına, beden kitle indekslerine göre incelendiğinde aralarında istatistiksel olarak anlamlı fark bulunmamıştır ( $>00.05)$. Ayrıca, beslenme $(\mathrm{X} 2=0.70, \mathrm{P}=0.70)$, sigara (Fisher $\mathrm{p}=0.70)$, alkol (Fisher $\mathrm{p}=1.00)$ alışkanlıkları, stresle başa çıkma yöntemleri $(\mathrm{X} 2=0.07, \mathrm{P}=0.79)$ ve düzenli olarak spor/egzersiz yapma sıklığı (Fisher $\mathrm{p}=0.18$ ) açısından da grupların birbirine benzer olduğu tespit edilmiştir.

Tablo 1. Katılımcıların Demografik Özelliklerine Göre Dağılımı

\begin{tabular}{|c|c|c|c|c|c|c|}
\hline \multirow[t]{2}{*}{ ÖZELLIKKLER } & \multicolumn{2}{|c|}{ Refleksoloji Grubu } & & Rutin Tedavi Grubu & \multicolumn{2}{|c|}{ Toplam } \\
\hline & Sayı & Yüzde & Sayı & Yüzde & Sayı & Yüzde \\
\hline \multicolumn{7}{|l|}{$\underline{\text { Sinıf }}$} \\
\hline 1. Sinif & 7 & 22.6 & 9 & 27.3 & 16 & 25.0 \\
\hline 2. Sinif & 10 & 32.3 & 15 & 45.4 & 25 & 39.1 \\
\hline 3. Sinif & 14 & 45.1 & 9 & 27.3 & 23 & 35.9 \\
\hline Test & & $\mathrm{X}^{2}=\mathbf{2 . 2 7}$ & $\mathbf{S D}=\mathbf{2}$ & $\mathrm{p}^{*}=0.32$ & & \\
\hline \multicolumn{7}{|l|}{ Yaș Grubu } \\
\hline$\overline{18-20 \text { Yaş }}$ & 14 & 45.2 & 13 & 39.4 & 27 & 42.2 \\
\hline 21-29 Yaş & 17 & 54.8 & 20 & 60.6 & 37 & 57.8 \\
\hline Test & & $\mathrm{X}^{2}=0.21$ & $\mathrm{SD}=1$ & $p^{*}=0.64$ & & \\
\hline \multicolumn{7}{|l|}{ İkamet Yeri } \\
\hline$\overline{\text { Evde ailesi ile birlikte }}$ & 8 & 25.8 & 10 & 30.3 & 18 & 28.1 \\
\hline Evde arkadaş/akrabaları ile birlikte & 8 & 25.8 & 7 & 21.2 & 15 & 23.4 \\
\hline & 15 & 48.4 & 16 & 48.5 & 31 & 48.5 \\
\hline Test & & $\mathrm{X}^{2}=0.25$ & $\mathrm{SD}=2$ & $\mathrm{p}^{*}=0.87$ & & \\
\hline \multicolumn{7}{|l|}{ Medeni Durum } \\
\hline$\overline{\text { Bekâr }}$ & 29 & 93.5 & 32 & 97.0 & 61 & 95.3 \\
\hline Evli & 2 & 6.5 & 1 & 3.0 & 3 & 4.7 \\
\hline Test & & Fisher & & $\mathrm{p}^{* *}=0.60$ & & \\
\hline \multicolumn{7}{|l|}{ Beden Kitle İndeksi } \\
\hline$\overline{\text { Zayıf }}$ & 9 & 29.0 & 12 & 36.4 & 21 & 32.8 \\
\hline Normal kilo & 22 & 71.0 & 20 & 60.6 & 42 & 65.6 \\
\hline Şişman & - & - & 1 & 3.0 & 1 & 1.6 \\
\hline Test & & $\mathrm{X}^{2}=1.46$ & $\mathrm{SD}=2$ & $\mathrm{p}^{*}=0.48$ & & \\
\hline TOPLAM & 31 & 100.0 & 33 & 100.0 & 64 & 100.0 \\
\hline
\end{tabular}

*ki-kare testi, ** Fisher's ki-kare testi 
Refleksoloji grubunun menstrüel dönemlerine göre refleksoloji uygulama süreçlerinde MDQ'den ve alt gruplarından aldıkları puan ortalamalarının dağılımı incelendiğinde; refleksoloji uygulanan iki siklus süresince MDQ'den aldıkları puan ortalamalarının menstrüel $(\mathrm{t}=7.94, \mathrm{p}=0.00)$, premenstrüel $(\mathrm{t}=7.99, \mathrm{p}=0.00)$ ve menstrüasyon sonrası dönemde $(\mathrm{t}=4.33$, $\mathrm{p}=0.00$ ) refleksoloji uygulaması öncesi MDQ'den aldıkları puan ortalamalarından daha düşük olduğu ve istatistiksel olarak anlamlı olduğu saptanmıştır(Grafik 1, p<0.05). MDQ'nin sekiz alt grubunda da refleksoloji uygulanan iki siklus süresince MDQ'den aldıkları puan ortalamalarının refleksoloji öncesi dönemden daha düşük olduğu ve istatistiksel olarak anlamlı olduğu saptanmıştır (Tablo 2).

Refleksoloji grubunun refleksoloji uygulaması bittikten sonraki iki siklus süresince MDQ'den aldıkları puan ortalamalarının menstrüel $(\mathrm{t}=76.94, \mathrm{p}=0.44)$ ve premenstrüel $(\mathrm{t}=1.30$, $\mathrm{p}=0.20$ ) dönemlerde refleksoloji uygulanan iki siklus süresince aldıkları puan ortalamalarından daha düşük olduğu fakat bunun istatistiksel olarak anlamlı olmadığı bulunmuştur. Menstrüasyon sonrası dönemde ise $(\mathrm{t}=2.51, \mathrm{p}=0.01)$ istatistiksel olarak anlamlı bir puan düşüşü saptanmıştır $(\mathrm{P}<0.05$, Grafik 1). Alt gruplarda ise; ağrı, su retansiyonu, konsantrasyon bozukluğu, davranış değişiklikleri ve kontrol alt gruplarında refleksoloji uygulaması bittikten sonraki iki siklus süresince MDQ'den aldıkları puan ortalamalarında anlamlı bir değişiklik olmamıştır. Otonomik reaksiyon alt grubunda ise premenstrüel dönemde ve diğer günlerde refleksoloji uygulaması bırakıldıktan sonra puan ortalamalarında istatistiksel olarak anlamlı yükselme olmuştur. Bunun tam aksine; negatif duygulanım alt grubunda premenstrüel dönemde, canlanma alt grubunda her üç dönemde de puan ortalamalarında düşüş devam etmiş ve istatistiksel olarak anlamlı bulunmuştur $(\mathrm{p}<0.05$, Tablo 2$)$.

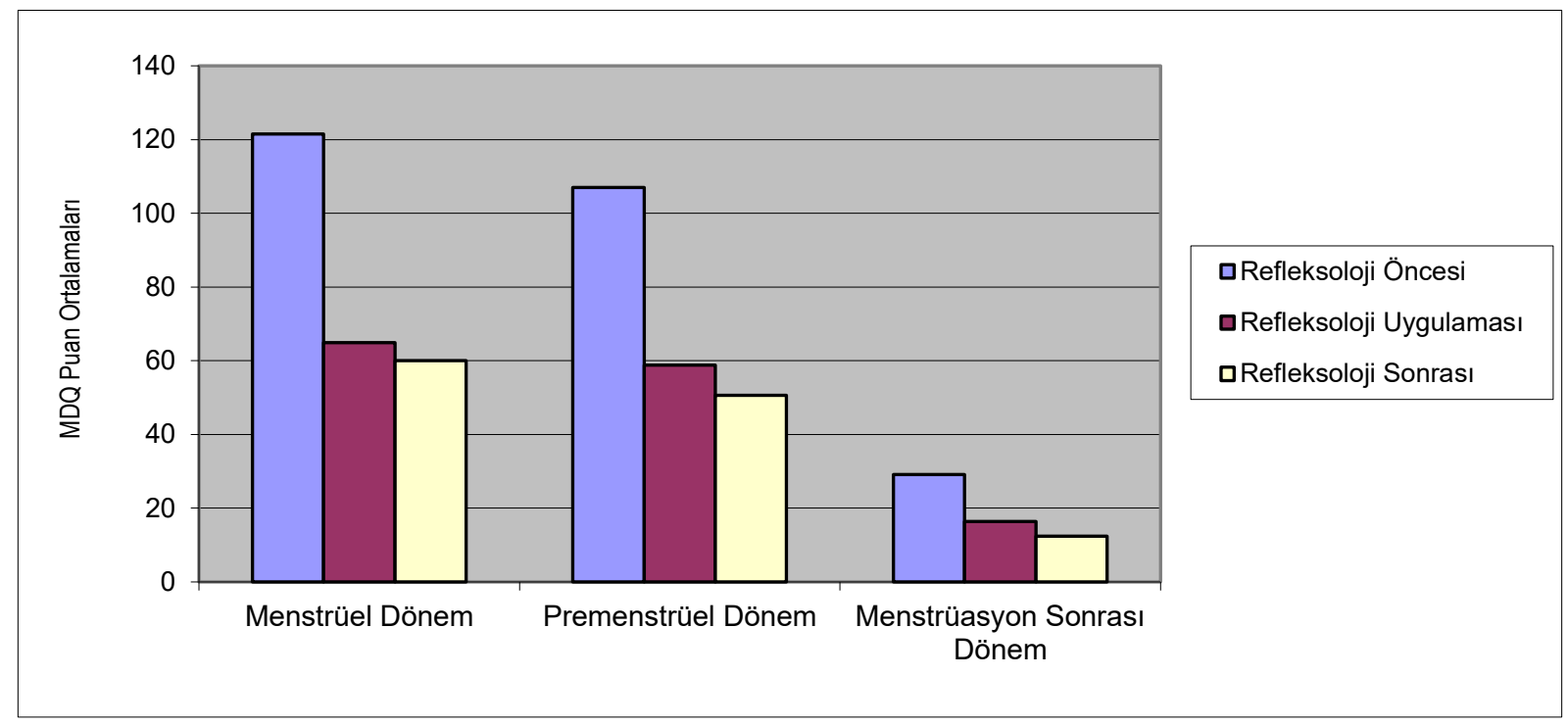

Grafik 1. Refleksoloji Grubunun Menstrüel Dönemlerine Göre MDQ’den Aldıkları Puan Ortalamalarının Zamansal Dağılımı 
Tablo 2. Refleksoloji Grubunun Menstrüel Dönemlerine Göre Refleksoloji Uygulama Süreci MDQ Alt Grubundan Aldıkları Puan Ortalamalarının Dağılımı

\begin{tabular}{|c|c|c|c|c|c|c|c|c|c|c|c|c|c|c|}
\hline \multirow{3}{*}{ 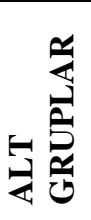 } & \multirow{3}{*}{$\begin{array}{l}\text { REFLEKSOLOJİ UYGULAMA } \\
\text { SÜRECLERİ }\end{array}$} & \multicolumn{13}{|c|}{ MENSTRÜEL SİKLUS DÖNEMLERİ } \\
\hline & & \multicolumn{4}{|c|}{ Menstrüel Dönem } & \multicolumn{5}{|c|}{ Premenstrüel Dönem } & \multicolumn{4}{|c|}{ Menstrüasyon Sonrası Dönem } \\
\hline & & $\mathbf{n}$ & $\overline{\mathbf{x}}$ & SD & $\mathbf{t}$ & $\mathbf{p}^{*}$ & $\overline{\mathbf{x}}$ & SD & $\mathbf{t}$ & $\mathbf{p}^{*}$ & $\overline{\mathbf{x}}$ & SD & $\mathbf{t}$ & $\mathbf{p}^{*}$ \\
\hline \multirow{4}{*}{$\sqrt{100}$} & Öncesi & 31 & 121.53 & 26.86 & \multirow[t]{2}{*}{7.94} & \multirow[t]{2}{*}{$\mathbf{0 . 0 0}$} & 107.03 & $35 . .91$ & \multirow[t]{2}{*}{7.99} & \multirow[t]{2}{*}{$\mathbf{0 . 0 0}$} & 29.14 & 19.54 & \multirow[t]{2}{*}{4.33} & \multirow[t]{2}{*}{$\mathbf{0 . 0 0}$} \\
\hline & Refleksoloji & 31 & 64.96 & 39.36 & & & 58.87 & 34.78 & & & 16.45 & 17.35 & & \\
\hline & Refleksoloji & 30 & 63.71 & 39.40 & \multirow[t]{2}{*}{0.76} & \multirow{2}{*}{0.44} & 57.00 & 33.76 & \multirow[t]{2}{*}{1.30} & \multirow[t]{2}{*}{0.20} & 16.66 & 17.61 & \multirow[t]{2}{*}{2.51} & \multirow[t]{2}{*}{0.01} \\
\hline & Sonrası & 30 & 60.08 & 43.63 & & & 50.65 & 44.33 & & & 12.43 & 18.54 & & \\
\hline \multirow{4}{*}{ क } & Öncesi & 31 & 11.40 & 3.97 & \multirow[t]{2}{*}{5.91} & \multirow[t]{2}{*}{0.00} & 13.58 & 4.63 & \multirow[t]{2}{*}{5.70} & \multirow[t]{2}{*}{0.00} & 1.58 & 1.77 & \multirow[t]{2}{*}{3.22} & \multirow[t]{2}{*}{0.00} \\
\hline & Refleksoloji & 31 & 6.56 & 4.42 & & & 8.88 & 5.04 & & & 0.91 & 1.20 & & \\
\hline & Refleksoloji & 30 & 6.33 & 4.30 & -1.83 & 0.07 & 8.56 & 4.80 & 1.53 & 0.13 & 0.88 & 1.20 & 0.93 & 0.35 \\
\hline & Sonrası & 30 & 7.45 & 4.69 & & & 7.58 & 4.80 & & & 0.70 & 1.29 & & \\
\hline \multirow{4}{*}{ 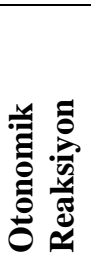 } & Öncesi & 31 & 9.32 & 4.26 & \multirow[t]{2}{*}{4.80} & \multirow[t]{2}{*}{0.00} & 6.11 & 3.58 & \multirow[t]{2}{*}{6.32} & \multirow[t]{2}{*}{0.00} & 0.74 & 1.05 & \multirow[t]{2}{*}{1.40} & 0.17 \\
\hline & Refleksoloji & 31 & 5.01 & 4.91 & & & 2.90 & 3.44 & & & 0.41 & 1.05 & & \\
\hline & Refleksoloji & 30 & 4.88 & 5.14 & 0.57 & 0.56 & 2.78 & 2.87 & -2.51 & 0.01 & 0.40 & 1.07 & -2.12 & 0.04 \\
\hline & Sonrası & 30 & 4.48 & 5.14 & & & 4.16 & 4.12 & & & 0.80 & 1.95 & & \\
\hline & Öncesi & 31 & 25.00 & 6.90 & 7.76 & 0.00 & 25.40 & 8.06 & 7.44 & 0.00 & 5.25 & 4.14 & 2.81 & 0.00 \\
\hline ఏ & Refleksoloji & 31 & 13.25 & 8.88 & & & 13.25 & 8.88 & & & 3.17 & 4.08 & & \\
\hline 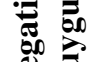 & Refleksoloji & 30 & $12 . .91$ & 8.82 & 0.95 & 0.34 & 12.91 & 8.82 & 7.18 & 0.00 & 3.18 & 4.15 & 1.17 & 0.09 \\
\hline $\bar{z}$ & Sonrası & 30 & 11.58 & 9.56 & & & 4.16 & 4.12 & & & 2.38 & 4.10 & & \\
\hline
\end{tabular}


Adnan Menderes Üniversitesi Sağlık Bilimleri Fakültesi Dergisi 2020: 4(2); 124-143

Journal of Adnan Menderes University Health Sciences Faculty

Tablo 2. Refleksoloji Grubunun Menstrüel Dönemlerine Göre Refleksoloji Uygulama Süreci MDQ Alt Grubundan Aldıkları Puan Ortalamalarının Dağılımı (Devam)

\begin{tabular}{|c|c|c|c|c|c|c|c|c|c|c|c|c|c|c|}
\hline \multirow{4}{*}{ 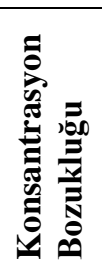 } & Öncesi & 31 & 18.11 & 8.00 & \multirow[t]{2}{*}{5.90} & \multirow[t]{2}{*}{0.00} & 14.70 & 8.58 & \multirow[t]{2}{*}{5.65} & \multirow[t]{2}{*}{0.00} & 4.80 & 4.81 & \multirow[t]{2}{*}{3.42} & \multirow[t]{2}{*}{0.00} \\
\hline & Refleksoloji & 31 & 8.32 & 7.48 & & & 6.87 & 6.70 & & & 2.27 & 3.43 & & \\
\hline & Refleksoloji & 30 & 8.10 & 7.50 & -0.11 & 0.90 & 6.53 & 6.53 & -0.14 & 0.88 & 2.35 & 3.46 & 1.05 & 0.30 \\
\hline & Sonrası & 30 & 8.21 & 8.00 & & & 6.65 & 8.05 & & & 1.95 & 3.44 & & \\
\hline \multirow{4}{*}{ 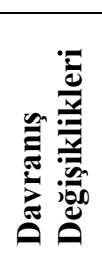 } & Öncesi & 31 & 16.14 & 4.67 & \multirow[t]{2}{*}{6.13} & \multirow[t]{2}{*}{0.00} & 10.06 & 4.94 & \multirow[t]{2}{*}{6.21} & \multirow[t]{2}{*}{0.00} & 2.12 & 2.29 & \multirow[t]{2}{*}{3.58} & \multirow[t]{2}{*}{0.00} \\
\hline & Refleksoloji & 31 & 8.85 & 7.01 & & & 4.46 & 4.60 & & & 0.72 & 1.25 & & \\
\hline & Refleksoloji & 30 & 8.83 & 7.13 & 1.51 & 0.14 & 4.30 & 4.58 & 1.15 & 0.25 & 0.75 & 1.26 & 1.94 & 0.06 \\
\hline & Sonrası & 30 & 7.55 & 6.82 & & & 3.45 & 4.83 & & & 0.41 & 1.26 & & \\
\hline \multirow{4}{*}{ 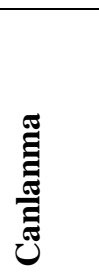 } & Öncesi & 31 & 9.00 & 4.67 & \multirow[t]{2}{*}{5.40} & \multirow[t]{2}{*}{0.00} & 9.19 & 5.15 & \multirow[t]{2}{*}{3.68} & \multirow[t]{2}{*}{0.00} & 7.91 & 5.21 & \multirow[t]{2}{*}{2.49} & \multirow[t]{2}{*}{0.01} \\
\hline & Refleksoloji & 31 & 5.11 & 3.74 & & & 6.01 & 4.60 & & & 5.74 & 5.93 & & \\
\hline & Refleksoloji & 30 & 5.21 & 3.75 & 2.51 & 0.01 & 6.15 & 4.62 & 3.25 & 0.00 & 5.86 & 5.98 & 2.98 & 0.00 \\
\hline & Sonrası & 30 & 3.46 & 3.51 & & & 3.73 & 3.94 & & & 3.46 & 5.06 & & \\
\hline \multirow{4}{*}{ 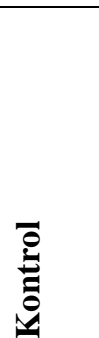 } & Öncesi & 31 & 9.29 & 4.43 & \multirow[t]{2}{*}{5.88} & \multirow[t]{2}{*}{0.00} & 8.40 & 4.68 & \multirow[t]{2}{*}{4.63} & \multirow[t]{2}{*}{0.00} & 2.12 & 2.69 & \multirow[t]{2}{*}{3.19} & \multirow[t]{2}{*}{$\overline{0.00}$} \\
\hline & Refleksoloji & 31 & 3.69 & 3.70 & & & 4.20 & 3.99 & & & 0.70 & 1.82 & & \\
\hline & Refleksoloji & 30 & 3.60 & 3.73 & \multirow[t]{2}{*}{0.43} & \multirow[t]{2}{*}{0.66} & 4.03 & 3.93 & \multirow[t]{2}{*}{0.77} & \multirow[t]{2}{*}{0.44} & 0.73 & 1.85 & \multirow[t]{2}{*}{0.20} & \multirow[t]{2}{*}{0.8} \\
\hline & Sonrası & 30 & 3.40 & 4.02 & & & 3.56 & 4.56 & & & 0.70 & 1.77 & & \\
\hline
\end{tabular}

*Paired Sample T Test 
Refleksoloji ve rutin tedavi grupları karşılaştırıldığında; refleksoloji uygulaması öncesi iki grubun her üç dönemde de MDQ'den aldıkları puan ortalamaların birbirine benzer olduğu, tespit edilmiştir $(\mathrm{P}<0.05$, Grafik 2). Refleksoloji uygulanan ilk siklusta refleksoloji grubunun MDQ'den aldıkları puan ortalamaların rutin tedavi grubundan daha düşük olduğu fakat bunun istatistiksel olarak anlamlı olmadığı belirlenmiştir. İkinci siklusta; menstrüel ve premenstrüel dönemlerde iki grup arasındaki puan farkının istatistiksel olarak anlamlı olduğu bulunmuştur (p<0.05, Tablo 3, Grafik 2).

Tablo 3. Menstrüel Dönemlere Göre Tedavi Süreci Birinci ve İkinci Sikluslarda Deney ve Kontrol Gruplarının MDQ’den Aldıkları Puan Ortalamalarının Dağılımı

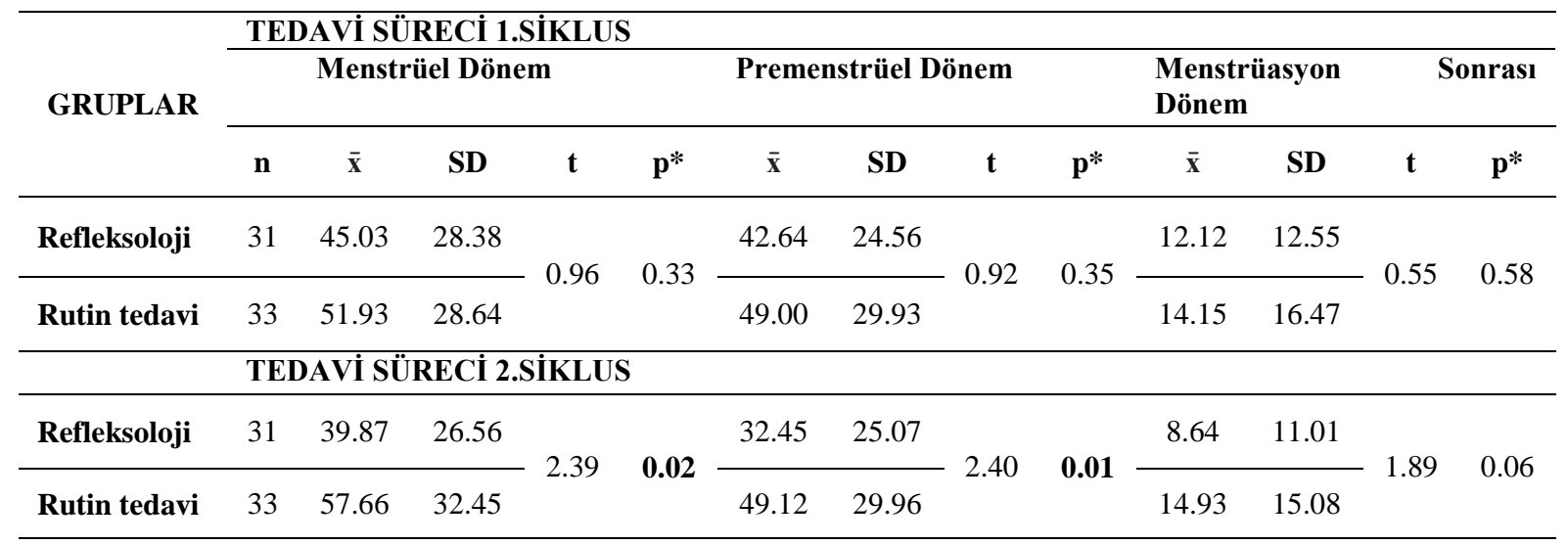

İkinci siklusta iki grup arasındaki alt gruplar incelendiğinde; refleksoloji grubunun premenstrüel dönem ağn $(\mathrm{t}=2.21, \mathrm{p}=0.03)$ ve otonomik reaksiyon $(\mathrm{t}=2.09, \mathrm{p}=0.04)$ alt gruplarının puan ortalamalarının istatistiksel olarak anlamlı derecede daha düşük olduğu saptanmıştır. Negatif duygulanım alt grubunun menstrüel dönem $(\mathrm{t}=2.11, \mathrm{p}=0.03)$, premenstrüel dönem( $\mathrm{t}=2.21, \mathrm{p}=0.03)$, konsantrasyon bozukluğu grubunun menstrüel dönem $(\mathrm{t}=3.10$, $\mathrm{p}=0.00)$, premenstrüel dönem $(\mathrm{t}=0.12, \mathrm{p}=0.01)$ puan ortalamaları arasında istatistiksel olarak anlamlı bir fark tespit edilmiştir ( $\mathrm{p}<0.05$, Tablo 3, Grafik 2).

\section{TARTIŞMA}

Refleksoloji stres ve gerilimi rahatlatmak, kan dolaşımını artırmak ve homeostazı sağlamak için tamamlayıcı bir tedavi olarak kullanılmaktadır (23,29-31). Refleks noktalarına basınç uygulanması ile periferal ve santral sinir sistemi uyarılarak iç organlar ve salgı bezlerinin sağlıklı çalışması, vücutta sağlıklı bir enerji akışının meydana gelmesi sağlanır $(31,39)$. Oleson ve Flocco (1993) iki siklus süresince, her hafta yarım saat, kulaklar, eller ve ayaklara refleksoloji masajı uygulamışlar ve premenstrüel dönem semptomlarında \%46 azalma kaydetmişlerdir (23). Bu çalışmada; menstrüel dönem semptomlarında \%46,54, premenstrüel dönem semptomlarında \%44.99 azalma olmuştur. Bu bulgular Oleson ve Flocco'nun araştırma- 


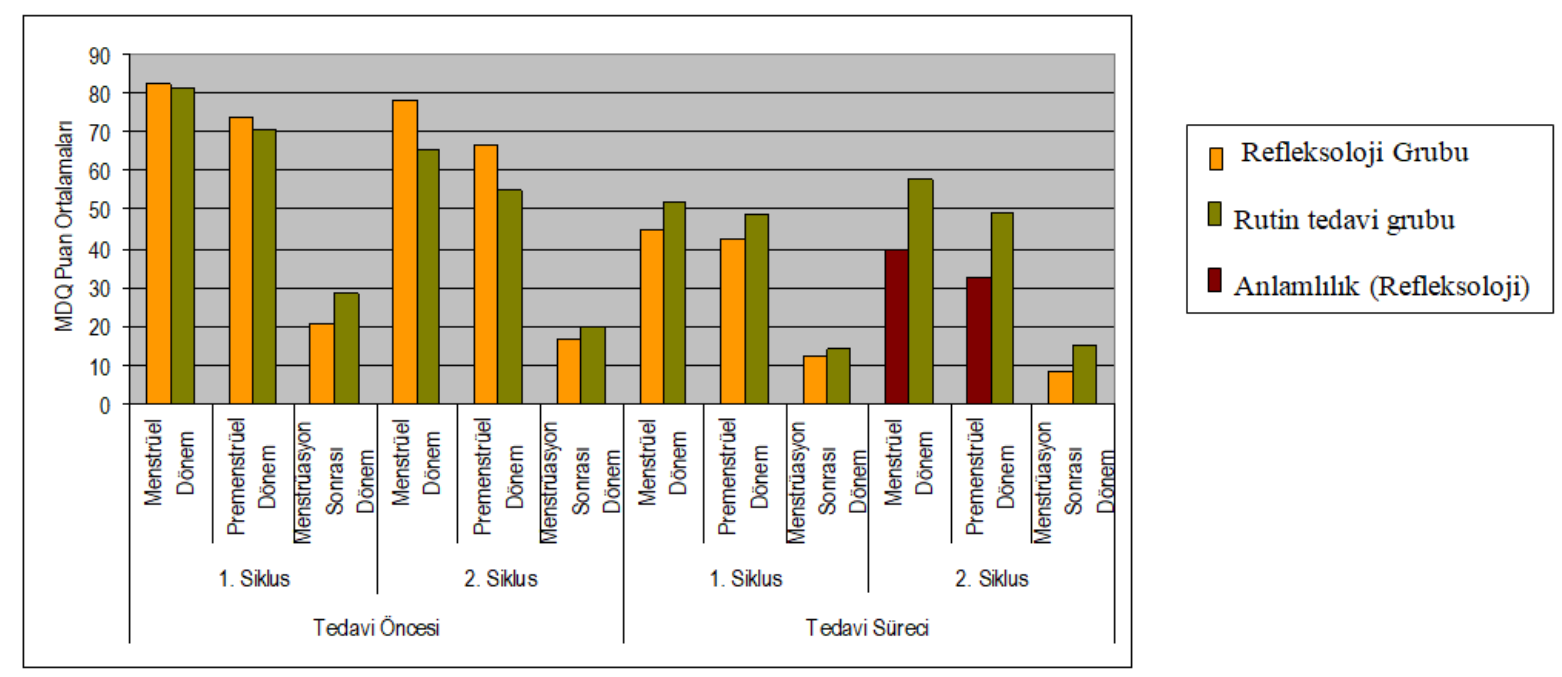

Grafik 2. Menstrüel Dönemlere Göre Tedavi Süreci Deney ve Kontrol Gruplarının MDQ'den Aldıkları Puan Ortalamalarının Dağılımı

sına uygunluk göstermektedir. Her iki çalışmada da aynı noktalara aynı sürede refleksoloji masajı uygulanmıştır, fakat farklı ölçüm aracı kullanılmıştır. Oleson ve Flocco’un çalışmasında katılımcıların semptomları günlük kaydetmesi istenmiştir, bu çalışmada semptomlar MDQ kullanılarak değerlendirilmiştir. Sonuçta çok yakın değerler elde edilmiştir. Benzer şekilde refleksolojisinin PMS ve dismonorenin fiziksel ve mental semptomları iyileştirmede etkili olduğunu tespit eden çalışmalar vardır $(37,39,40)$.

Refleksolojinin nasıl çalıştığı kesin olarak açık olmamakla birlikte literatürde plasebo etki, tedavi etkileşimi ve dokunma etkisinden elde edilen bir miktar rahatlamanın yapabileceğinden çok daha büyük fizyolojik etkiler gösterdiği konusunda bilgiler vardır $(23,38,39)$. Premenstrüel sendromda plasebo etkinin \%20'den az olduğu bildirilmiştir. Oleson ve Flocco'nun araştırmasında yanlış noktalara yapılan refleksoloji yanıtı \%19 olarak kaydedilmiştir (23).

Çalışmada refleksoloji bırakıldıktan sonraki iki siklusta da semptomlarda bir artış olmamış, hatta istatistiksel olarak anlamlı olmamakla birlikte bir miktar daha azalma devam etmiştir (Grafik 1). Oleson ve Flocco'nun araştırmasında da refleksoloji sonrası etkinin devam ettiği bulunmuştur (23). Bu bulgularla refleksoloji masajı uygulamanın perimenstrüel distresi hafiflettiği, refleksolojinin etkisinin bırakıldıktan sonraki iki siklusta da devam ettiği söylenebilir.

Günümüzde perimenstrüel semptomların tedavisinde ilk seçenek NSAID'lerdir. NSAID'lerin tüm ay boyunca kullanılmaları gerekmediğinden oral kontraseptiflere göre hasta uyumunun daha iyi olduğu kabul edilmektedir (26). Literatür taraması sırasında, refleksoloji ile NSAID’lerin karşılaştırıldığı bir çalışmaya rastlanamamıştır. Fakat primer dismenoreli üniversite öğrencileri ile yapılan bir araştırmada akupresür, Ibuprofen ve sham akupresürü (uygun olmayan noktaya yapılan akupresür) karşılaştırmış, akupresür ve Ibuprofen arasında fark olmadığı fakat her ikisinin de sham akupresürden daha etkili olduğu bulunmuştur (41). Başka bir çalışmada akupunktur ve NSAID’leri karşılaştırılmış ve altı aylık izlem sonunda birbirine yakın etkiler gösterdikleri belirlemiştir (42). Valiani ve ark. (2010) yapmış oldukları refleksoloji ve İbuprofen uygulamasının dismenore üzerindeki etkilerinin karşılaştırılması adlı 
çalışmada refleksolojinin ağrı yoğunluğunu ve süresini azaltmada Ibuprofen'den daha etkili olduğunu göstermişlerdir (43). Sriprasert ve ark. (2015) orta şiddetli dismenore tedavisinde kombine oral kontraseptiflere karşı akupunktur etkililiği isimli çalışmada, özellikle kombine oral kontraseptif kullanımının uygun olmadığı olgularda akupunkturun dismenoreyi hafifletmek için alternatif bir seçenek olarak kullanılabileceğini belirlemişlerdir (44).

$\mathrm{Bu}$ çalışmada, tedavi öncesi iki siklusta ve tedavi süreci birinci siklusta iki grup arasında fark belirlenmezken tedavi süreci ikinci siklusta refleksoloji grubunun puanlarının rutin tedavi grubundan daha düşük olduğu saptanmıştır (Tablo 3, Grafik 2). Burada, refleksolojinin kümülatif bir etki gösterdiği söylenebilir. Çalışma sonuçları Wu ve arkadaşlarının (2007) kulak üzerindeki özel noktalara vurma ve baskıyla yaptıkları çalışmanın sonuçları ile benzerlik göstermektedir. Wu ve ark.(2007) üç siklus takip ettikleri primer dismenoreli olgular üzerinde oral Indoxmeixin'den daha yüksek etki elde etmişlerdir (45).

Menstrüel distres şikâyet listesi 47 semptomdan ve sekiz alt semptom grubundan oluşmaktadır. Bunlar; ağrı, su retansiyonu, otonomik reaksiyon, negatif duygulanım, konsantrasyon bozukluğu, davranış değişikliği, canlanma ve kontroldür. Sekiz alt semptom grubunun refleksoloji uygulaması ile zaman içindeki değişimi ayrı ayrı analiz edilmiştir (Tablo 2).

Ağrı alt grubu; kaslarda gerginlik- sertleşme, baş ağrısı, karın ağrısı-kramplar, sırt-bel ağrısı, genel kırıklık-ağrılar ve yorgunluk semptomlarını içermektedir. Menstrüel dönem ağrı puanlarında \%43.36 azalma, premenstrüel dönem ağrı puanlarında \%49.68 azalma olduğu, premenstrüel dönem ağrı semptomlarında daha fazla gerileme olduğu gözlenmiştir. Refleksoloji uygulaması ile ağrıların hafiflediği ve etkinin uygulama sonrası da devam ettiği söylenebilir. Literatürde, refleksolojinin kanser ağrısını anlamlı derecede azalttığı yer almaktadır $(29,46,47)$. Refleksolojinin sinir noktalarını belirli tekniklerle uyarmasının ortaya elektrokimyasal mesajlar çıkardığı, bu mesajların nöronlar yardımıyla ilgili organları uyardığı savunulmaktadır. Ayrıca, masaj olduğu için ten tene temasın endorfin ve diğer beyin salgılarının salınımına yol açtığı, bunun da ağrının azalmasına yardımcı olduğu ve iyilik hissini artırdığı görüşü vardır $(29,35,48)$. Endorfinler nöronlar arası sinaptik mesafede impuls iletimini sağlayan transmitter maddeler gurubundandır (49). İlaveten, ağrı kesici etki özel refleks noktalarına yapılan masajın kapı kontrol mekanizmasını çalıştırması ile elde edilmiş olabilir (48). Benzer etki mekanizmalarıyla çalışan, akupunktur, akupresür ve TENS'le yapılmış araştırmalarda da dismenore ve premenstrüel ağrıların azaltılmasında başarılı sonuçlar elde edilmiştir (41,42,44,50-54).

Chang ve Jun (2003) üniversite öğrencileriyle yaptıkları araştırmalarında, SP-6 noktasına yaptıkları 20 dakikalık akupresür sonucunda 30. dakikada istatistiksel olarak anlamlı derecede dismenorenin hafiflediğini ve norepinefrin seviyesinin değiştiğini belirlemişlerdir (51). Yang ve Huang (2008) akupunkturun etkisini araştırmak için laboratuvarda farelerle yaptıkları araştırmalarında, akupunkturun dismenoreyi hafiflettiğini bulmuş ve hormon reseptörleri üzerine etkili olduğu görüşüne varmışlardır (55). Mohamed ve ark. (2016) ayak refleksolojisi ve gevşeme egzersizlerinin premenstrüel sendromları azaltmasına yönelik yaptıkları çalışmasında bir gruba sadece gevşeme egzersizlerini, diğer gruba gevşeme egzersizlerine ek olarak ayak refleksolojisi uygulamış ve solunum hızı, kalp atım hızı, plazma kortizol seviyesi ve günlük semptomları değerlendirmiştir. Her iki grupta da istatistiksel olarak anlamlı bir düşüş tespit edilmiş ancak gevşeme egzersizleri ile birlikte ayak refleksolojisi 
uygulanan grubun puanları istatistiksel olarak daha anlamlı bulunmuştur (30). Prema ve ark. (2017) ayak refleksolojisinin premenstrual sendrom ve dismenoreyi rahatlatıcı etkisi üzerine yaptıkları çalışmada refleksolojinin ağrı yoğunluğunu ve süresini azaltmada etkili olduğunu belirlemiş̧lerdir (37). Azima ve ark. (2015) yapmış oldukları refleksoloji ve masaj terapisinin primer dismenore üzerindeki etkilerinin karşılaştırılması isimli çalışmada aromaterapi masajı ve refleksolojinin ağrı yoğunluğunu ve primer dismenore süresini azalttığı tespit edilmiştir (56).

Toplam puan ortalamalarına benzer şekilde; tedavi süreci birinci siklusta; ağrı alt grubu puanları açısından iki grup arasında bir farklılık olmadığı, ikinci siklusta, refleksoloji grubunun premenstrüel dönem puanlarının istatistiksel olarak anlamlı derecede düşük olduğu saptanmıştır (Grafik 2). Ağrının daha yoğun olduğu menstrüel dönemde farklılık olmadığı halde, premenstrüel dönemdeki gruplar arası farklılığı açıklamak zordur. Fakat her iki dönemde de refleksolojinin etkili olduğu söylenebilir. Literatürde NSAID’lerin primer dismenorede \%7090 etkili olduğu, etkisiz olduğu durumlarda başka bir NSAID grubun denenmesi gerektiği önerilmektedir. Ayrıca, başarısız sonuçlarda uygun doz ve sıklıkta kullanılmamasının etkili olduğu belirtilmektedir (26). Buna karşın, refleksolojinin premenstrüel dönemdeki ağrı oluşum mekanizmasını etkilemiş ve ağrının oluşmasını engellemiş olması da bir olasılık olarak düşünülebilir.

Su retansiyonu alt grubu; kilo alma, ciltte leke-sivilce, memelerde ağrı ya da hassasiyet, karında, memelerde şişme semptomlarını içermektedir. Literatürde premenstrüel dönemde en sık rastlanan somatik semptom olarak karında şişme ve göğüslerde hassasiyet bildirilmektedir $(1,7,8,13)$. Menstrüel dönem su retansiyonu puanlarında $\% 42.45$, premenstrüel dönem su retansiyonu puanlarında \%34.60 azalma olduğu, ancak premenstrüel dönem su retansiyonu semptomlarında ağrıya nazaran daha az gerileme olduğu belirlenmiştir. Bu durum, literatürle uyumludur $(57,58)$. Bir çalışmada gebeliğin son trimestirindeki ayak ödemini azaltmak için kullanılan iki refleksoloji metodununda kontrol grubundan daha etkili olduğu ancak lenfatik refleksoloji tekniğinin daha etkili olduğu bulunmuştur (59). Refleksoloji uygulamasının su retansiyonu semptomlarını azalttığı ve etkinin refleksoloji uygulaması bırakıldıktan sonraki iki siklusta da devam ettiği söylenebilir.

Menstrüel dönem otonomik reaksiyon puanlarında \%46.24, premenstrüel dönem otonomik reaksiyon puanlarında \%52.53 azalma olduğu, premenstrüel dönem otonomik reaksiyon semptomlarında daha fazla gerileme olduğu gözlenmiştir. Bu sonuç literatür ile uyumludur (23). Tedavi süreci ikinci siklusta refleksoloji grubunun semptomlarında rutin tedavi grubuna göre daha fazla azalma saptanmıştır. Refleksolojinin stres ve gerilimi rahatlatarak, kan dolaşımını arttırarak ve hemostazisi düzenleyerek (29-31,60) etkili olmuş olabileceği düşünülebilir. İlaveten, rutin tedavide kullanılan NSAID'lerin gastrointestinal yakınmalar başta olmak üzere baş dönmesi, sinirlilik, kulak çınlaması, bulanık görme gibi yan etkileri vardır $(8,26,61)$. Otonomik reaksiyon alt grubunun baş dönmesi-baygınlık hissi, soğuk terleme, bulantı-kusma ve ateş basması semptomlarından oluştuğunu düşünürsek belki daha açıklayıcı olabilir. Kızılkaya ve Coşkun'un araştırmasında, menstrüel dönemde en fazla soğuk terleme ve ateş basması, premenstrüel dönemde ise baş dönmesi-baygınlık hissi ve ateş basması semptomları olduğu belirlenmiştir (57).

Negatif duygulanım alt grubu; yalnızlık, anksiyete (sıkıntı), ruhsal (mood) değişiklikler, ağlama, aşırı hassaslık-alınganlık, gerginlik, üzgün-hüzünlü olma (depresyon) ve aşırı hareketler (çabuk parlama) semptomlarını içermektedir. Premenstrüel sendromun psikolojik 
semptomlarının, kadınları en fazla tedavi arayışına götüren semptomlar olduğu bildirilmiştir. Çabuk sinirlenme, depresyon ve anksiyete ilk sıralarda yer almaktadır $(2,5,63)$ Refleksoloji uygulaması ile menstrüel dönem negatif duygulanım puanlarında $\% 47.00$, premenstrüel dönem negatif duygulanım puanlarında \%47.83 azalma olduğu belirlenmiştir. Refleksoloji uygulaması ile menstrüel ve premenstrüel dönemlerin semptomlarında aynı derecede gerilediği söylenebilir. Ayrıca premenstrüel dönemde, negatif duygulanım puanlarındaki düşüşün refleksoloji bırakıldıktan sonra da istatistiksel olarak anlamlı olduğu saptanmıştır (Tablo 2). Oleson ve Flocco (1993) kadınların premenstrüel dönemdeki testlerinde belirlenen yüksek adrenokortikal reaktiviteye paralel olarak menstrüasyon sonrası dönemden çok daha fazla, psikolojik distres yaşadıklarını belirtmişlerdir. Akupunkturun plazma ACTH ve kortizol seviyesindeki düşüşü göstermesi gibi, refleksolojinin de adrenokortikal stres reaktivitesinde ciddi bir düşüş sağlayabileceğini ve bunun uygulama sürekliliğiyle devam ettirilebileceğini savunmuştur. Gerçek refleksoloji uygulaması yapılan kadınların çok büyük relaksasyon yaşadıkları bildirilmiştir (23). Çıtak ve Terzioğlu üniversite öğrencilerinde yaptıkları araştırmalarında, yaşama olumsuz bakan, kötümser ve stresle baş etme düzeyi yetersiz olan kız öğrencilerde dismenorenin daha şiddetli yaşandığını saptamışlardır (26). Kanser hastalarıyla yapılmış refleksoloji araştırmalarında refleksolojinin çok iyi bir relaksasyon yarattı̆̆ı, anksiyeteyi anlamlı derecede düşürdüğü ve yaşam kalitesini artırdığı bildirilmiştir $(24,46,64)$ Ayrıca, masaj, egzersiz ve progresif gevşeme gibi farmakolojik olmayan diğer metotların da perimenstrüel negatif duygulanım semptomlarının azaltılmasında yararlı olduğu belirlenmiştir $(17,57,58,64)$. Birçok araştırmacı stresle başa çıkma yollarının öğrenilmesinin yararlı olacağı görüşündedir $(10,11,17,26,38)$ Tedavi süreci ikinci siklusta refleksoloji grubunun menstrüel ve premenstrüel dönem puanlarının rutin tedavi grubundan daha düşük olduğu ve bunun istatistiksel olarak anlamlı olduğu bulunmuştur. Bu sonuç, refleksolojinin stres ve gerilimi azaltıcı etkilerine paralel bir sonuç olarak kabul edilebilir

Konsantrasyon bozukluğu alt grubu; uykusuzluk, unutkanlık, sersemlik, kararsızlık, zihni bir noktaya toplamada güçlük, dikkat dağınıklığı, dalgınlık, dikkatsizlik sonucu oluşan küçük kazalar, hareketlerde uyum yetersizliği semptomlarını içermektedir. Bu semptomlar iş ve okul başarısını azaltıcı etkiler yapmaktadır. Yapılmış araştırmalarda tedavi arayışına neden olan yakınmalar arasında üçüncü sırayı almaktadır $(26,58,62)$ Bir araştırmada dismenoresi olan üniversite öğrencilerinde konsantrasyon bozukluğu \%48.3 olarak bildirilmiştir (26). Refleksoloji uygulaması ile konsantrasyon bozukluğu puanlarında menstrüel dönemde \%54.05, premenstrüel dönemde \%53.26 azalma olduğu gözlenmiştir. Araştırma bulguları literatür ile uyumludur $(23,37)$. Oleson ve Flocco kadınların çoğunluğunun 30 dakikalık refleksoloji seansı süresince uykuya daldığını ve sonraki gün çok daha enerjik olduğunu kaydetmiştir (23). Bu araştırma esnasında da araştırmacının notlarında benzer ifadeler vardır. Öğrencilerin 30 dakikalık refleksoloji seansı süresince uyukladıkları gözlenmiştir. Daha sonraki görüşmelerde; refleksoloji uygulamasının yapıldığı günün akşamında daha rahat uyuduklarını, sonraki gün sabah çok daha erken kalktıklarını ve uykularını almış hissettiklerini, gün içinde dersleri çok daha rahat takip ettiklerini ifade etmişlerdir. Perimenstrüel semptomları rahatlatmak için masaj, egzersiz ve progresif gevşeme gibi diğer metotlarla yapılmış araştırmalarda da benzer iyileşmeler kaydedilmiştir $(17,57,58,64)$.

Davranış değişiklikleri alt grubu; eğitim ya da çalışma gücünde azalma, yataktan çıkmak istememe-yatakta kalma, evden dışarı çıkamama-işe gidememe, sosyal etkinliklerden 
kaçınma ve verimlilikte azalma semptomlarından oluşmaktadır. Perimenstrüel distres, seksüel olgunluk dönemindeki kadınların büyük bir bölümünde görülmesi, iş yaşamını, sosyal ilişkilerini ve aile yaşantısını ciddi boyutlarda etkilemesi nedeniyle yalnızca bir kadın sağlığı sorunu değil bir toplum sağlı̆̆ı sorunu olarak da karşımıza çıkmaktadır (13,38). Özellikle adölesanların perimenstrüel yakınmalar nedeniyle okul ve çalışma yaşamlarını olumsuz yönde etkileyerek iş gücü kayıplarına ve okul devamsızlıklarına neden olmaktadır $(1,18,26,37)$ Hatta literatürde; primer dismenorenin okul devamsızlığının birinci nedeni olduğu (10), iş yaşamında da iş kalitesinin düştüğü ve iş kazası riskinin arttığı yer almaktadır (9). Refleksoloji uygulaması ile davranış değişiklikleri puanlarında menstrüel dönemde $\% 45.16$, premenstrüel dönemde \%55.68 azalma olduğu, premenstrüel dönem davranış değişiklikleri semptomlarında daha fazla gerileme olduğu gözlenmiştir.

Araştırmada, canlanma alt grubu puanlarının negatif semptomlar içeren diğer yedi alt gruptan farklı olarak menstrüasyon sonrası dönemde daha yüksek olduğu belirlenmiştir. $\mathrm{Bu}$, beklendik bir durumdur ve literatüre paralellik göstermektedir $(17,57)$

Menstrüel dönem kontrol alt grubu puanlarında \%60.27, premenstrüel dönem kontrol alt grubu puanlarında \%50.00 azalma olduğu, menstrüel dönem kontrol alt grubu semptomlarında daha fazla gerileme olduğu belirlenmiştir. Bu sonuç literatür ile uyumludur (23). Bu sonuçlar doğrultusunda; refleksoloji uygulamasının kontrol alt grubu semptomlarını azalttığı ve etkinin refleksoloji uygulaması bırakıldıktan sonraki iki siklusta da devam ettiği söylenebilir.

Sekiz alt semptom grubunun puan değişimleri menstrüel dönemlere göre incelendiğinde; en yüksek puan değişimi (\%60.27) kontrol alt grubunun menstrüel döneminde kaydedilmiştir. En düşük puan değişimi ise (\%34.60) su retansiyonu alt grubunun premenstrüel döneminde kaydedilmiştir. Hernandez-Reif ve arkadaşlarının masaj araştırmalarında da benzer sonuçlar vardır. Kısa dönemde anksiyete ve negatif duygulanımın azaldığı, uzun dönemde ağrı ve su retansiyonunun azaldığı belirtilmiştir (58).

\section{SONUÇ VE ÖNERİLER}

Araştırma bulgularına göre; iki siklus süresince, (sekiz seans) haftada yarım saat süre ile, kulaklara, ellere ve ayaklarara refleksoloji masajı uygulamanın perimenstrüel distresi hafiflettiği, refleksolojinin etkisinin bırakıldıktan sonra hemen kaybolmadığı söylenebilir. Refleksolojinin stres ve gerilimi rahatlatıcı, ağrıyı azaltıcı, kan dolaşımını artırıcı ve hemostazisi sağlayıcı özelliklerinin sağlığı yükseltici olması ve yan etkilerinin olmaması nedeniyle perimenstrüel distreste tamamlayıcı bir tedavi olarak kullanılması önerilebilir. Ayrıca rutindeki tedavileri diğer sağlık sorunları nedeniyle kullanamayanlar için semptomları azaltıcı veya iş konsantrasyonunu arttırmak isteyenler için destekleyici bir seçenek olarak düşünülebilir.

\section{Araştırmanın Etik Yönü}

Çalışmaya başlamadan önce Etik Kurul Onayı (08/12/2006 tarihli 2006-109 sayıl1) ve kurum izni (21/12/2006 tarihli B.30.2.EGE. 0.82.00.00-2331 sayılı) alınmıştır. Örneklem seçim aşamasında tüm katılımcılara araştırmanın amacı açıklanmış bilgilendirilmiş sözlü onamları ve uygulama aşamasında bilgilendirilmiş yazılı onamları alınmıştır. 


\section{KAYNAKLAR}

1. Coşkun, A., Kızılkaya, N. (1995). İstanbul ilinde yaşayan doğuran çağı kadınlarda görülen perimestrual şikâyet durumunun yaş grupları açısından değerlendirilmesi. Hemşirelik Bülteni, 9(35), 35-44.

2. Kızılkaya, N. (1994). Perimenstrual distres ve hemşirelik yaklaşımı. Hemşirelik Bülteni, 8(31), 84-91.

3. Kirkpatrick, M. K, Brewer, J. A, Stoks, B. (1990). Efficacy of self-care measures for perimentrual syndrome (PMS). JAN Leading Global Nursing Researh,15(3),281-285.

4. Güneş, G, Pehlivan, E, Genç, N., Eğri M. (1997). Malatya'da lise öğrencilerinde premenstrüel sendrom sıklı̆̆ı. Turgut Ö̈zal Tip Merkezi Dergisi, 4(4), 403-406.

5. Karadağ, F. (2001). Adet öncesi disforik bozukluk, Psikiyatri Dünyası, 5(1), 11-14.

6. Kızılkaya, N. (1995). Dismenore. Sendrom -Aylık Aktuel Tip Dergisi, Mayıs, 48-53.

7. Taşkın, L. (2016). Doğum ve kadın să̆lı̆̆ hemşireliği. Ankara: Akademisyen Kitapevi.

8. Berek, J. S., Çev.Ed. Erk, A. (2004). Novak jinekoloji. İstanbul: Nobel Tıp Kitabevleri

9. Çıtak, N. Terzioğlu, F. (2002) Abant İzzet Baysal Üniversitesinde öğrenim gören kız öğrencilerin primer dismenoreye ilişkin bilgi ve uygulamaları. Sağlık ve Toplum, 12(3), 69-80.

10. Durain, D. (2004). Primary Dysmenorrhea: assessment and management update. Journal of Midwifery \& Women's Health, 49(6), 520-528.

11. Öztürk, A. (2004). Kadın hastalıkları ve doğum polikliniklerine başvuran kadınlarda dismenore sıklığ1 ve etkileyen faktörler. MN Klinik Bilimler \& Doktor 10, 2: 208-213.

12. Afifi, O. A. W., Fahmy, N. M., Omran, A. A. H., Abd-Elmoniem, S.O. (2017). Effect of self feet reflexology on relieving premenstrual syndrome. Menoufia Nursing Journal, 2(2), 3-21.

13. Akyılmaz, F., Özçelik, N., Polat, M. G. (2003). Premenstrüel sendrom görülme sıklı̆̆1. Göztepe Tip Dergisi,18:106-109.

14. Kim, S. Y., Park H. J., Lee, H., Lee, H. (2011). Acupuncture for premenstrual syndrome: a systematic review and meta-analysis of randomised controlled trials. BJOG,118,899915.

15. Walsh, S., Ismaili, E., Naheed, B., O'Brien, S. (2015). Diagnosis, pathophysiology and management of premenstrual syndrome. The Obstetrician \& Gynaecologist, 17(2):99104. doi: $10.1111 /$ tog. 12180.

16. Domoney, G. L., Vashisht, A., Studd, W. W. (2003). Use of complementary therapies by women attending a specialist premenstrüel syndrome clinic. Gyn. End., 17(1), 1318.

17. Goodale, I. L., Domar, A. D., Benson, H. (1990). Alleviation of premenstrüel symptoms with the relaxation response. Obstetrics \& Gynecology, 75(4), 649-655.

18. Hernandez-Reif, M. (2000). Premenstrüel symptoms are relieved by massage therapy. J Psychosom Obstet Gynecol, 21, 9-15.

19. Jang, H., Lee, M. S. (2004). Effect of qi therapy (external qigong) on premenstrüel syndrome: a randomized placebo-controlled study. The Journal of Alternative and Complementary Medicine, 10(3), 456-462.

20. Jun E. M., Chang S., Kang D. H., Kim S. (2006). Effects of acupressure on dysmenorrhea and skin temperature changes in college students: A non-randomized controlled trial. International Journal of Nursing Studies, 44, 973-981.

21. Palas Karaca, P., Kizilkaya Beji, N. (2015). Premenstrual sendromunun tanı ve tedavisinde kanıt temelli yaklaşımlar ve hemşirelik bakımı. Balıkesir Sağlık Bilimleri Dergisi, 4(3),178-186.

22. Ernst, E. (2006). Acupunktur-a critical analysis. Journal of Internal Medicine, 259, 125 137. 
23. Oleson, T., Flocco, W. (1993) Randomized controlled study of premestrual symptoms treated with ear, hand, and foot reflexology. Obstetrics \& Gynecology, 82(6), 906-911.

24. Stevinson, C., Ernst, E. (2001). Complementary/Alternative therapies for premenstrüel syndrome: A systematic review of randomized controlled trials. Am J Obstet Gynecol, 185(1), 227-235.

25. Walsh, M. J. (1999). A radomized, placebo-controlled clinical trial on the efficacy of chiropratic therapy on premenstrüel syndrome. Journal of Manupulative and Physiological Therapeutics. 22(9),582-585.

26. Çalışkan, E., Özeren, S., Çorakçı, A. (2004). Premestrüel sendromlar ve primer dismenore. Galenos Tip Dergisi, 7(98), 15-18.

27. Long, L, Huntley, A, Ernst, E. (2001). Which complementary and alternative therapies benefit which conditions? A Survey of opinions of 223 professional organizations. Complementary Therapy in Medicine, 9, 178-185.

28. Emslie, M. J., Campbell, M. K., Walker, K. A. (2002). Changes in public awareness of, attitudes to, and use of complementary therapy in North East Scotland: Surveys in 1993 and 1999. Complementary Therapy in Medicine, 10, 148-153.

29. Stephenson, N. L. N., Weinrich, S. P., Tvakoli, A. S. (2000). The effects of foot reflexology on anxiety and pain in patients with breast and lung cancer. Oncol Nurs Forum, 27, 1

30. Mohamed, M. A, Bandrawy, A. M. E, Gabr, A. A. (2016). Do foot reflexology and relaxation traning decrease premenstrual symptoms in adolescent females. Int $J$ Physiother, 3(5),522-528

31. Çevik, K. (2013). Hemşirelikte tamamlayıcı ve alternatif tedavi: refleksoloji. Ege Üniversitesi Hemşirelik Fakültesi Dergisi, 29(2), 71-82.

32. Frankel, B. M. S. (1997). The effect of reflexology on baroreceptor reflex sensitivity, blood pressure and sinus arrhytmia. Complementary Therapy in Medicine, 5,80-84.

33. White, A. R., Williamson, J., Hart, A., Ernst, E. (2000). A blinded investigation into the accuracy of reflexology charts. Complementary Therapy in Medicine, 8, 166-172.

34. Botting, D. (1997). reviev of literature on the effectiveness of reflexology. Complementary Therapies in Nursing \& Midwifery, 3,123-130.

35. Wilkinson, L. (2002). The house of lords selsect commitee for science and technology. their report on complementary and alternative medicine and its implications for reflexology. Complementary Therapy in Nursing \& Midwifery, 8, 91-100.

36. Vennells, D. F., Çev. Soner, S. (2004). Refleksoloji, Ege Meta Yayınları, İzmir, 2. Bask1.

37. Prema, S., Ramaiah, R., Ahmed Elsayed, L., Nomani, İ. (2017). Effect of foot reflexology on the relief of premenstrual syndrome and dysmenorrhea. International Journal of Science and Research (IJSR),6 (11), 2095-2100

38. Kızılkaya, N, Tuncel, N. (1994). Perimenstrual şikayetlerin hafifletilmesinde hemşirelik girişimlerinin etkinliği. Hemşirelik Bülteni, 8(32), 66-79.

39. Jacob, J. (2013). Effectiveness of reflexology on premenstrual syndrome among students in selected nursing colleges, mangalore.(Yayınlanmamış yüksek lisan tezi ). Rajiv Gandhi University of Health Sciences, Mangalore

40. Fard, S. A., Dolatain, M., Heshmat, R., Majd, H.A. (2013). Effect of foot reflexology on physical and psychological symptoms of premenstrual syndrome. Pejouhandeh Shahıd Beheshtı University Of Medical Sciences, 18(1),8-15.

41. Pouresmail Z, Ibrahimzadeh R, (2002). Effects of acupresure and ibuprofen on the severity of primary dysmenorrhea. J Tradit Chin Med., 22(3), 205-210.

42. Iorno, V., Burani, R., Bianchini, B., Minelli, E., Martinelli, F. Ciatto S. (2008) Acupunture treatment of dysmenorrhea resistant to conventional medical treatment. Evid Based Complement Alternat Med., 5(2), 227-230. 
43. Valiani, M., Babaei, E., Heshmat, R., Zare, Z.(2010). Comparing the effects of reflexology methods and Ibuprofen administration on dysmenorrhea in female students of Isfahan University of Medical Sciences. Iran J Nurs Midwifery Res. 15(11), 371378.

44. Sriprasert, İ., Suerungruang, S., Athilarp, P., Matanasarawoot, A., Teekachunhatean, S. (2015). Efficacy of Acupuncture versus Combined Oral Contraceptive Pill in Treatment of Moderate-to-Severe Dysmenorrhea: A Randomized Controlled Trial. Hindawi Publishing Corporation Evidence-Based Complementary and Alternative Medicine, VolumeArticle ID 735690, 10 pages.

45. Wu R. D., Zhang H. D., Lin L. F. (2007). Observation on ear point tapping and pressing therapy for treatment of primary dysmenorrhea. Zhongguo Zhen Jiu, 27(11), 815-817.

46. Fadıloğlu, Ç., Usta Yeşilbalkan, Ö. (2005). Kanserli hastalarda ayak refleksolojisinin ağrı ve anksiyete üzerine etkisinin incelenmesi. XVI. Ulusal Kanser Kongresi Özet Kitab1, 20-24 Nisan, Antalya, 213.

47. Quattrin, R., Zanini, A., Buchini, S., Turello, D., Annunziata, M. A., Vidotti, C., et al.(2006). Use of reflexology foot massage to reduce anxiety in hospitalized cancer patients in chemotherapy treatment: Merhodology and autcomes. Journal of Nursing Management, 14,96-105.

48. Tiran, D., Chummun, H. (2005). The physiological basis of reflexology and its as a potantial dianostic toll. Complementary Therapies in Clinical Practice, 11(1), 58-64.

49. Sezen, K. (2002). Akupunktur Teorik ve Pratik. Ankara:MN Medikal \& Nobel Tip Kitap Sarayı.

50. ChaeY., Kim H.Y., Lee H.J., Park H.J., Hahm D.H., An K., et al. (2007). The alteration of pain sensitivity at disease-specific acupuncture points in premenstrual syndrome. $J$ Physiol Sci., 57(2),115-119.

51. Chang S. B., Jun E. M. (2003) . Effects of SP-6 acupressure on dysmenorea, cortisol, epinephrine and norepinephrine in the college students. Taehan Kanho Hakhoe Chi, 33(7), 1038-1046.

52. Chen H. M., Chen C. H. (2004). Effects of acupressure at the sanyinjiao point on primary dysmenorrhoea. Journal of Advenced Nursing, 48 (4), 380-387.

53. Habek D., Habek J. C., Barbir A. (2002). Using acupuncture to treat premenstrualsyndrome. Arch Gynecol Obstet, 267(1), 23-26.

54. Lewers, D., Clelland, J. A., Jackson, J. R., Varner, R. E., Bergman, J. (1989) Transcutaneous electrical nerve stimulation in the relief of primary dysmenorrhea. Phys Ther, 69(1), 3-9.

55. Yang Y. Q., Huang G. Y. (2008). Study on Effects of Acupuncture on Mice Dysmenorrhea Model and the Mechanism. Zhongguo Zhen Jiu, 28(2), 119-121.

56. Azima, S, Bakhshayesh, H. R., Mousavi, S., Ashrafizaveh, A. (2015). Comparison of the effects of reflexology and massage therapy on primary dysmenorrheal. Biomedical Research, 26(3), 471-476

57. Kızılkaya, N., Coşkun, A. (1994). Perimenstrual şikayetlerin eğzersiz, proğrasif gevşeme ve diyet yöntemleriyle hafifletilmesi durumunun irdelenmesi ve yöntemlerin etkinlik durumunun değerlendirilmesi. Ege Üniversitesi Hemşirelik Yüksekokulu Dergisi, 10(3), 1-17.

58. Hernandez-Reif, M. (2000). Premenstrüel symptoms are relieved by massage therapy. J Psychosom Obstet Gynecol.21, 9-15.

59. Mollart, L. (2003). Single-blind trial addressing the differential effects of two reflexology techniques versus rest, on ankle and foot oedema in late pregnancy. Complementary Therapy in Nursing \& Midwifery, 9, 203-208. 
60. Wang, M. Y., Tsia, P. S., Lee, P. H., Cang, W. Y., Yang, C. M. (2008). The efficacy of reflexogy: Systematic review. Journal of Advenced Nursing, 62 (5), 512-520.

61. www.ilacrehberi.com( Erişim Tarihi 15 Temmuz 2008).

62. Müderris, İ. İ., Gönül, A. S., Sofuoğlu, S., Taşcı, S., Bayatlı. M. (1999). Genç kadınlarda premestrüel disforik bozukluk prevelans1. Klinik Psikiyatri, 2, 197-201.

63. Wringht, S., Courtney, U., Donnelly, C., Kenny, T., Lavin, C. (2002). Clients'perceptions of the benefits of reflexology on their quality of life. Complementary Therapy in Nursing \& Midwifery, 8, 69-76.

64. Kim, J. S., Jo, Y. J., Hwang, S. K. (2005). The effects of abdominal meridian massage on menstrual cramps and dysmenorrhea in full-time employed women. Taehan Kanho Hakhoe Chi, 35(7),1325-1332. 